\title{
Inhibition of lipolytic reactions during wet storage of T-Isochrysis lutea biomass by heat treatment
}

Lieselot Balduyck ${ }^{1}$, Céline Dejonghe ${ }^{1}$, Peter Goos ${ }^{2}$, Etienne Jooken ${ }^{3}$, Koenraad Muylaert ${ }^{4}$, Imogen Foubert ${ }^{1^{*}}$

${ }^{1}$ KU Leuven Kulak, Research Unit Food \& Lipids, E. Sabbelaan 53, 8500 Kortrijk, Belgium Leuven Food Science and Nutrition Research Centre (LFoRCe), KU Leuven, Kasteelpark Arenberg 20, 3001 Leuven, Belgium.

${ }^{2}$ KU Leuven, Department of Biosystems, MeBioS division, Kasteelpark Arenberg 30, 3001 Leuven, Belgium.

University of Antwerp, Department of Engineering Management, Prinsstraat 13, 2000 Antwerpen, Belgium

${ }^{3}$ Technologiecluster Bioengineering Technology, Campus Brugge, Spoorwegstraat 12 - bus 7913, 8200 Sint-Michiels, Belgium

Departement Microbiële en Moleculaire Systemen, KU Leuven, Kasteelpark Arenberg 23 - bus 246, 3001 Leuven

${ }^{4}$ KU Leuven Kulak, Laboratory Aquatic Biology, E. Sabbelaan 53, 8500 Kortrijk, Belgium

${ }^{*}$ Corresponding author:

Email: imogen.foubert@kuleuven.be

Tel: +32 56246173 


\section{Abstract}

Microalgal lipids have a huge potential in several applications such as biofuels, food and feed. However, enzymatic lipolytic reactions during wet storage cause the formation of substantial amounts of free fatty acids (FFA), which give several problems for these applications. In this study, a full factorial $\left(3^{2}\right)$ design with varying time and temperature was used to optimize a heat treatment, thatinactivates lipolytic enzymes in the wet paste of T-Isochrysis lutea. Therefore, the FFA and lipid content were evaluated at three time points $\left(0,3\right.$ and 7 days) during wet storage at $4^{\circ} \mathrm{C}$. A treatment of at least 8 minutes at $80^{\circ} \mathrm{C}$ was found to inactivate the lipolytic enzymes. A second experiment elucidated that this optimal treatment had no negative impact on fatty acid composition, peroxide value, phenolic content or carotenoid content. A short heat treatment, thus, enables wet storage of microalgal paste to several days at $4^{\circ} \mathrm{C}$.

\section{Keywords}

T-Isochrysis lutea; Lipolysis; Free fatty acids; Stability; Storage 


\section{Introduction}

Microalgae are an extremely diverse group of unicellular microorganisms living in aquatic systems. Several species possess a large amount of lipids and are, thus, promising lipid sources for applications in feed, fuel, food and high value applications (e.g., cosmetics, pharmaceuticals, nutraceuticals) ${ }^{1,2}$. In addition, the lipid fraction of some microalgae contains substantial amounts of long-chain omega-3 polyunsaturated fatty acids, particularly EPA (eicosapentaenoic acid, C20:5n-3) and DHA (docosahexaenoic acid, C22:6n-3), which are considered as health promoting compounds ${ }^{3}$. The lipid content and composition depends on the microalgal species, but also on the cultivation conditions ${ }^{4,5}$.

For all applications of microalgal lipids mentioned above, their stability is of major importance. One of the most impactful stability problems for microalgal lipids is lipolysis, whereby fatty acids are released from the backbones of, among others, triacylglycerols, phospholipids and glycolipids. This process induces the formation of high amounts of free fatty acids (FFA), which are detrimental for several reasons. First, the presence of FFA complicates the production process of biodiesel from oils containing more than $0.5 \%$ FFA when using alkali catalysts since FFA can react in a saponification reaction with these alkali catalysts, leading to a reduced efficiency and higher purification costs ${ }^{6,7}$. Second FFA can cause off-flavors in food and high value applications. In addition, FFA are prone to oxidation reactions 8,9 and have been shown to have a pro-oxidative effect ${ }^{10}$. These induced oxidation reactions can have a negative impact on the nutritional value and the flavor ${ }^{11}$ and can cause deposit formation in biodiesel production systems ${ }^{12}$.

It has been demonstrated before that lipolysis in microalgae is mainly a problem during the wet stages of the production process, being harvesting, cell disruption, wet storage and possibly wet lipid extraction ${ }^{13-15}$. During these wet stages, especially the integrity of the cells plays a major role in the lipolytic stability. Balduyck et al. ${ }^{14}$ showed no FFA formation in intact Nannochloropsis cells during 7 days of wet storage at $4^{\circ} \mathrm{C}$, while in cells disrupted by high pressure homogenization, lipolysis started very rapidly during and immediately after cell disruption. In microalgae species with a weak cell 
structure (e.g., T-Isochrysis lutea), rupture already occurs during harvesting, resulting in a very rapid increase of the FFA content ${ }^{13,14}$. Although rupture of the cells is detrimental to lipid stability, it is often unavoidable or even necessary to improve the lipid extraction efficiency of the cells ${ }^{16,17}$. In addition, when using wet extraction techniques in which the lipids are extracted directly from the wet biomass, the time spent as a wet biomass paste increases, making lipolysis a possibility that can possibly also pose problems.

Lipolytic reactions occurring in microalgal biomass are mostly caused by endogenous enzymes (lipases), as has been shown by isolating and characterizing these enzymes from, among others, Spirulina platensis ${ }^{18}$, Chatonella marina ${ }^{19}$, Botryococcus sudeticus ${ }^{20}$ and Nannochloropsis oceanica ${ }^{21}$. Also several genetic studies elucidated the presence of genes encoding for carboxylesterase and/or lipase-like enzymes in Isochrysis galbana ${ }^{22-24}$ and Phaeodactylum tricornutum ${ }^{25}$. Most of these studies reported a temperature optimum for the enzymes between 25 and $45^{\circ} \mathrm{C}$ and a pH optimum between 6.5 and 9. In contrast, Savvidou et al. ${ }^{21}$ found very thermostable lipases in Nannochloropsis oceanica, which were even more active when treated at $100^{\circ} \mathrm{C}$ for 60 minutes.

One of the possible methods to avoid extensive FFA formation during wet storage, cell disruption or wet extraction, is to inactivate the lipolytic enzymes at an early stage by a heat treatment. A few studies used a boiling water treatment of the wet biomass of Isochrysis galbana, T-Isochrysis lutea ${ }^{24}$, Skeletonema costatum ${ }^{26}$ and Pseudo-nitzschia ${ }^{27}$, to lower the FFA content in the biomass. Also in other research fields struggling with lipolysis problems, heat treatments are commonly used. Rice bran, oat and wheat germ also possess high lipase activities and experience a limited shelf life with accompanying off-flavors, decrease of nutritional value and unsuitability for applications, unless a heat treatment is applied ${ }^{9,28-31}$. However, heat treatments can promote lipid oxidation due to the higher temperatures to which the lipids are exposed ${ }^{9}$. In addition, heat-sensitive antioxidants broken down during the heat treatment can also cause a lowered oxidative stability during prolonged storage ${ }^{9,32}$. 
These oxidation reactions also have a negative impact on flavor and on the nutritional value due to a loss of among others the health promoting polyunsaturated fatty acids ${ }^{11}$.

The substrate specificity, temperature and $\mathrm{pH}$ optimum and, consequently, also the time-temperature combination of the heat treatment, necessary for denaturation of the enzymes, depends strongly on the source of the lipases ${ }^{33}$. This makes optimization specific for microalgae and differentiation between microalgal species necessary. After all, working at temperatures below the inactivation temperature could possibly activate the lipolytic enzymes instead of inactivating them, which would cause even higher FFA contents.

In this study, the heat treatment was optimized to enable wet storage of $T$-Isochrysis lutea for a longer term (7 days) without FFA formation. A full factorial design $\left(3^{2}\right)$ with varying time-temperature combinations was used to determine the minimum treatment required for inactivation of the lipolytic enzymes. In a follow-up experiment, two adequate treatments were selected to verify whether other quality attributes remained unchanged by the treatment. Therefore, the two treatments were compared to the control (no heat treatment) in terms of omega-3 fatty acids, oxidative stability and content of pigments (carotenoids and chlorophylls) and phenolic compounds, which have also been shown to possess some beneficial health effects ${ }^{34}$.

To the best of our knowledge, this is the first study investigating heat treatment of microalgal biomass to inactivate lipases, allowing for wet storage. Also, the influence of the heat treatment on quality attributes has not been investigated before.

\section{Materials and methods}

\subsection{Cultivation and harvesting}

Cultivation of T-Isochrysis lutea, formerly named Isochrysis sp. (CCAP 927/14; Culture Collection of Algae and Protozoa, Oban, United Kingdom) was performed in pilot scale (30 L) photobioreactors as described in Balduyck et al. ${ }^{13}$. Briefly, Wright's Cryptophyte (WC) medium ${ }^{35}$ to which $30 \mathrm{~g} / \mathrm{L}$ artificial 
sea salt (Homarsel, Zoutman, Roeselare) was added, was used as cultivation medium. The $\mathrm{pH}$ was controlled at $8.5 \pm 0.2$, while the temperature was controlled at $20^{\circ} \mathrm{C}$ and a light-dark cycle of 16 light hours and 8 dark hours was installed. The growth rate was monitored by measuring the optical density at $750 \mathrm{~nm}$ allowing to determine the harvesting time. The microalgae were harvested in the early stationary phase by centrifugation using a continuous lamella centrifuge (4000 g until saturation). Cultivation and harvesting was performed separately for the two experiments (described in 2.2 and 2.3).

\subsection{Influence of different heat treatments on FFA production during wet storage}

In a first experiment, the harvested microalgal paste (approximately $7 \%$ dry matter) was homogenized by stirring and divided in glass tubes $(10 \mathrm{~mL})$. These were put in a water bath at a certain temperature for a certain time period. The temperature and time were varied according to a full factorial $\left(3^{2}\right)$ design, with temperatures $65^{\circ} \mathrm{C}, 80^{\circ} \mathrm{C}$ and $95^{\circ} \mathrm{C}$ and time periods 3,8 and 13 minutes. After the heat treatment, the tubes were brought immediately into an ice bath and kept there until they reached ice temperature. The control sample was not subjected to a heat treatment and was kept at room temperature during the treatment of the other samples. To concentrate the samples to a lower volume, they were centrifuged once more at $1000 \mathrm{~g}$ for 10 minutes, after which the supernatant was decanted. The center point treatment $\left(80^{\circ} \mathrm{C}-8 \mathrm{~min}\right)$ was performed in triplicate, while all other treatments were performed only once. The sample obtained after each treatment was divided in three portions, so that one portion could be frozen $\left(\right.$ at $-80^{\circ} \mathrm{C}$ ) and freeze-dried immediately (T0), while the other portions were stored for 2 days (T1) and 7 days (T2) at $4^{\circ} \mathrm{C}$ before freezing and freeze-drying to monitor the FFA production during wet storage. Analyses of the total lipid content and the FFA content were conducted on the dried biomass.

\subsection{Influence of selected time - temperature treatments on quality attributes}

For the second part of the experiment, the procedure described in $\S 2.2$ was repeated (dry matter content was now approximately 4\%) for a control sample (which was not heat-treated) and for two 
heat treatments selected based on the results of the experiment described in $\S 2.2: 8$ minutes at $80^{\circ} \mathrm{C}$ (treatment $1, \mathrm{TRT} 1$ ) and 3 minutes at $95^{\circ} \mathrm{C}$ (treatment 2, TRT2). The actual temperature in the biomass paste during and immediately after the treatment was followed by a thermocouple (Figure 1). Each treatment was performed twice, so that one sample was immediately frozen at $-80^{\circ} \mathrm{C}$ and subsequently freeze-dried (TO), while the other sample was stored for 7 days at $4^{\circ} \mathrm{C}$ before freezing and freeze-drying (T2). Analysis of the total lipid content, FFA content, fatty acid profile, oxidative stability, pigment content and phenolic content were conducted on the dried biomass.

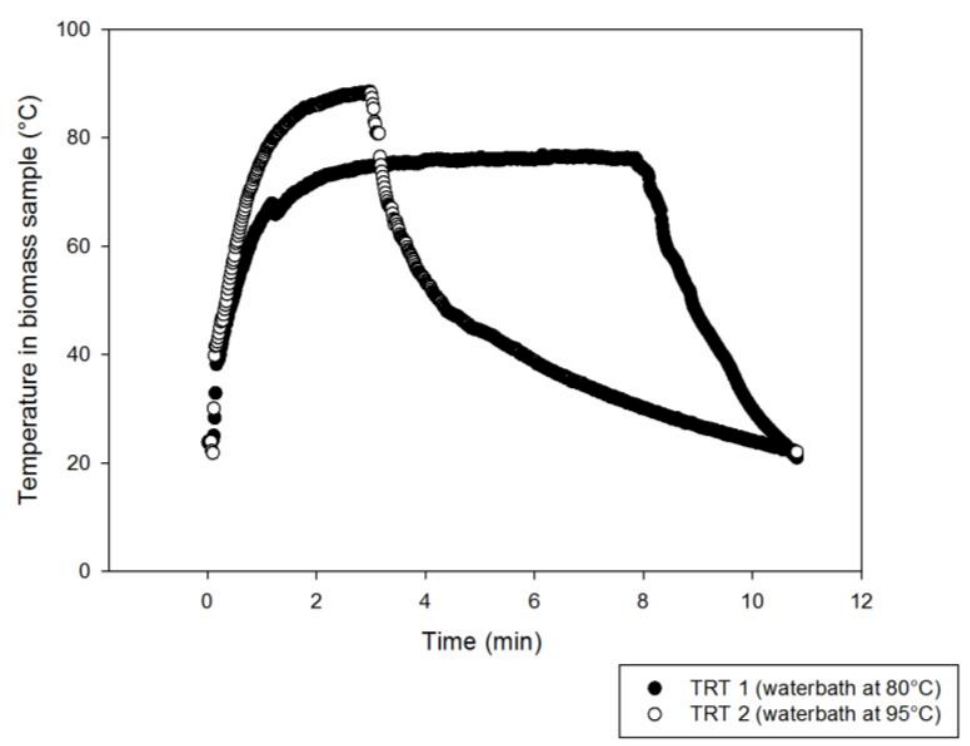

Figure 1: Actual temperature in T-Isochrysis lutea wet biomass $\left({ }^{\circ} \mathrm{C}\right)$ during heat treatment at $80^{\circ} \mathrm{C}$ for $8 \mathrm{~min}(\mathrm{TRT}$ 1) and at $95^{\circ} \mathrm{C}$ for $3 \mathrm{~min}$ (TRT 2) and subsequent cooling in an ice bath.

\subsection{Total lipid content}

The total lipid content (on dry basis) of the biomass samples was determined by chloroform/methanol (1:1) extraction as described in Ryckebosch et al. ${ }^{36}$. All extractions were conducted in triplicate.

\subsection{FFA content}


The FFA content in the total lipid fraction ( $\S 2.4$ ) was determined by derivatization of the FFA to diethylamide derivatives and subsequent analysis by gas chromatography, according to the method described in Balduyck et al. ${ }^{13}$, based on Kangani et al. ${ }^{37}$. Before extraction, 5 mg of lauric acid (C12:0) (Nu-Check Prep, Elysian, USA) was added as an internal standard. The peak area of this internal standard was then compared to the total peak area of the chromatogram to calculate the FFA content. This analysis was performed in triplicate on each sample.

\subsection{Fatty acid profile and omega-3 content}

The fatty acid profile was determined by methylesterification of the lipids in the total lipid fraction (§ 2.4) according to the method described in Lemahieu et al. ${ }^{38}$. Before extraction, $5 \mathrm{mg}$ of lauric acid (C12:0) (Nu-Check Prep, Elysian, USA) was added as an internal standard. To $5 \mathrm{mg}$ of the extracted lipids, dissolved in $1 \mathrm{~mL}$ toluene, $2 \mathrm{~mL}$ of $1 \%$ sulfuric acid in methanol was added. Fatty acid methyl esters (FAME's) were formed during incubation overnight at $50^{\circ} \mathrm{C}$. After cooling to room temperature, $5 \mathrm{~mL}$ of $5 \% \mathrm{NaCl}$ was added to improve phase separation. Subsequently, the FAME's were extracted with $3 \mathrm{~mL}$ hexane and diluted to a concentration of $0.5 \mathrm{mg} / \mathrm{mL}$ for chromatographic analysis. The FAME's were separated by gas chromatography with cold on-column injection and detected by flame ionization detector (GC-FID) (Trace GC Ultra, Thermo Scientific, Interscience, Louvain-la-Neuve, Belgium). An EC Wax column (length: $30 \mathrm{~m}$, ID $0.32 \mathrm{~mm}$, film: $0.25 \mu \mathrm{m}$ ) (Grace, Lokeren, Belgium) was used and the time-temperature program applied was $70-180^{\circ} \mathrm{C}\left(10^{\circ} \mathrm{C} / \mathrm{min}\right), 180-235^{\circ} \mathrm{C}\left(4{ }^{\circ} \mathrm{C} / \mathrm{min}\right)$, $235{ }^{\circ} \mathrm{C}$ (4.75 min). Identification of the fatty acids was conducted using a standard mixture containing 35 different FAME (Nu-Check Prep, Elysian, USA). Peak areas were quantified with the software Chromcard (Interscience, Louvain-la-Neuve, Belgium).

\subsection{Oxidative stability}

The oxidative stability of the microalgal lipids was analyzed by determining the peroxide value (PV) as a measure of the amount of primary lipid oxidation products (hydroperoxides). The PV was determined by the spectrophotometric ferrous oxidation - xylenol orange (FOX) method as described in 
Ryckebosch et al. ${ }^{39}$. This spectrophotometric method measures the amount of ferrous ions $\left(\mathrm{Fe}^{2+}\right)$ oxidized to ferric ions $\left(\mathrm{Fe}^{3+}\right)$ by peroxides in the samples. The ferric ions form a blue-purple complex with xylenol orange, of which the absorbance is measured at $560 \mathrm{~nm}$.

\subsection{Pigment content and composition}

Carotenoids and chlorophylls in the microalgal biomass samples were extracted with acetone/methanol (7:3). Therefore, $5 \mathrm{~mL}$ of acetone/methanol (7:3) was added to $25 \mathrm{mg}$ of freezedried biomass. After homogenization, the mixture was centrifuged for 10 minutes at $750 \mathrm{~g}$. The supernatant was transferred to another tube, while the remaining pellet was extracted three more times in the same way. The collected supernatants were diluted and filtered for HPLC analysis. Extraction was conducted in duplicate on each sample.

The pigment composition of each extract was analyzed by HPLC with a photodiode array detector (PAD) (Alliance, Waters, Zellik, Belgium) set at $436 \mathrm{~nm}$. A Nova-Pak C18 column (4 $\mu \mathrm{m}, 3.9 \times 150 \mathrm{~mm}$ ) with a $\mathrm{C} 18$ guard column, in a column oven set at $30^{\circ} \mathrm{C}$, was used for separation. The mobile phases used were methanol/ammonium acetate buffer $(\mathrm{pH} 7.2,0.5 \mathrm{M})(8: 2)$ (solvent $\mathrm{A})$, acetonitrile/milliQ water (9:1) (solvent B) and ethylacetate (solvent C). The following gradient was used: $100 \%$ A to $100 \%$ $B(0-3 \mathrm{~min}), 100 \% \mathrm{~B}$ to $40 \% \mathrm{~B}$ and $60 \% \mathrm{C}(3-14 \mathrm{~min})$, isocratic at $40 \% \mathrm{~B}$ and $60 \% \mathrm{C}(14-23 \mathrm{~min}), 40 \%$ B and $60 \%$ C to $100 \%$ B (23- $25 \mathrm{~min}$ ), 100\% B to $100 \%$ A (25 - 26 min). Standards obtained from SigmaAldrich (chlorophyll a, pheophytin a, fucoxanthin, beta-carotene) and from DHI lab products (Horsholm, Denmark) (chlorophyll C2, violaxanthin, diadinoxanthin, antheraxanthin, diatoxanthin, lutein, zeaxanthin) were used for identification. External calibration curves were used for quantification of the pigments in the samples. Each extract was injected twice.

\subsection{Phenolic content}

The phenolic content was determined by the spectrophotometric method described in Goiris et al. ${ }^{40}$. First, an extract of phenolic compounds was prepared by mixing $100 \mathrm{mg}$ of microalgal biomass with 2 
$\mathrm{mL}$ of ethanol/water (3:1). After centrifugationat $4500 \mathrm{~g}$ for 10 minutes, the supernatant was transferred to another tube, while the pellet was extracted a second time by the same method. The pooled extracts were diluted to obtain values according to the external standard curve. Next, $200 \mu \mathrm{L}$ of the diluted extract was mixed with $1.5 \mathrm{~mL}$ Folin-Ciocalteu reagent and allowed to stand at room temperature for 5 minutes. Subsequently, $1.5 \mathrm{~mL}$ of sodium bicarbonate solution ( $60 \mathrm{~g} / \mathrm{L})$ was added and incubated for 90 minutes at room temperature. Subsequently, the absorbance at $750 \mathrm{~nm}$ was measured. Each biomass sample was analyzed in duplicate. The total phenolic content was calibrated against a standard curve of gallic acid ( 25 to $150 \mathrm{mg} / \mathrm{L}$ ) and expressed as $\mathrm{mg}$ gallic acid equivalents (GAE) per g biomass.

\subsection{Statistical analysis}

For the first part of the experiment, involving the factorial design, a response surface model in the time and temperature of the heat treatment was fitted to the data using the weighted least squares option in the statistical software JMP Pro 12.1 (SAS Institute Inc., Cary (North Carolina) USA). The model involved linear effects, quadratic effects and the two-way interaction effects. As recommended in the literature on response surface methodology ${ }^{41,42}$, the levels of the variables time and temperature were rescaled to the interval $[-1,1]$. The inverse variances of the responses, representing the error in the measurement, determined by the analyses in triplicate, were used as weights in the weighed least squares analysis.

Separate response surface models were fitted to the FFA content at T0, T1 and T2. When analyzing the T0 responses, the values of the samples treated at $65^{\circ} \mathrm{C}-13$ minutes and $80^{\circ} \mathrm{C}-3$ minutes were not included, as something went wrong during freeze-drying resulting in abnormal FFA contents. The best fitting models for T0, T1 and T2, obtained after discarding non-significant model terms, were used to set up contour plots showing the joint effects of time and temperature on the FFA content.

\section{Results and discussion}




\subsection{Influence of different heat treatments on FFA production during wet storage}

The $T$-Isochrysis lutea biomass, after a heat treatment at $65^{\circ} \mathrm{C}, 80^{\circ} \mathrm{C}$ or $95^{\circ} \mathrm{C}$ for 3,8 or 13 minutes, was compared to the non-treated control biomass. The FFA content and the total lipid content (expressed as percentage of the biomass) at T0 (immediately after the treatment), T1 (after 2 days of wet storage at $4^{\circ} \mathrm{C}$ ) and T2 (after 7 days of wet storage at $4^{\circ} \mathrm{C}$ ) are displayed in Figure 2 . The results of the analyses of the samples treated at $65^{\circ} \mathrm{C}-13$ minutes and $80^{\circ} \mathrm{C}-3$ minutes for T0 are not shown, as unfortunately something went wrong during freeze-drying and abnormal values resulted. It was however impossible to redo only these samples and use the results to apply the model as the batch effect would then prevent a proper comparison of the two new samples to those of the initial experiment. As the aim of the experiment was to determine whether lipolysis still occurred after the heat treatment, and whether the lipases were thus still active, the comparison of the amount of FFA between $\mathrm{T} 1$ and $\mathrm{T} 2$ provided sufficient information, without having to redo the whole experiment. The missing values were as such not critical for the conclusions drawn. 
(A)

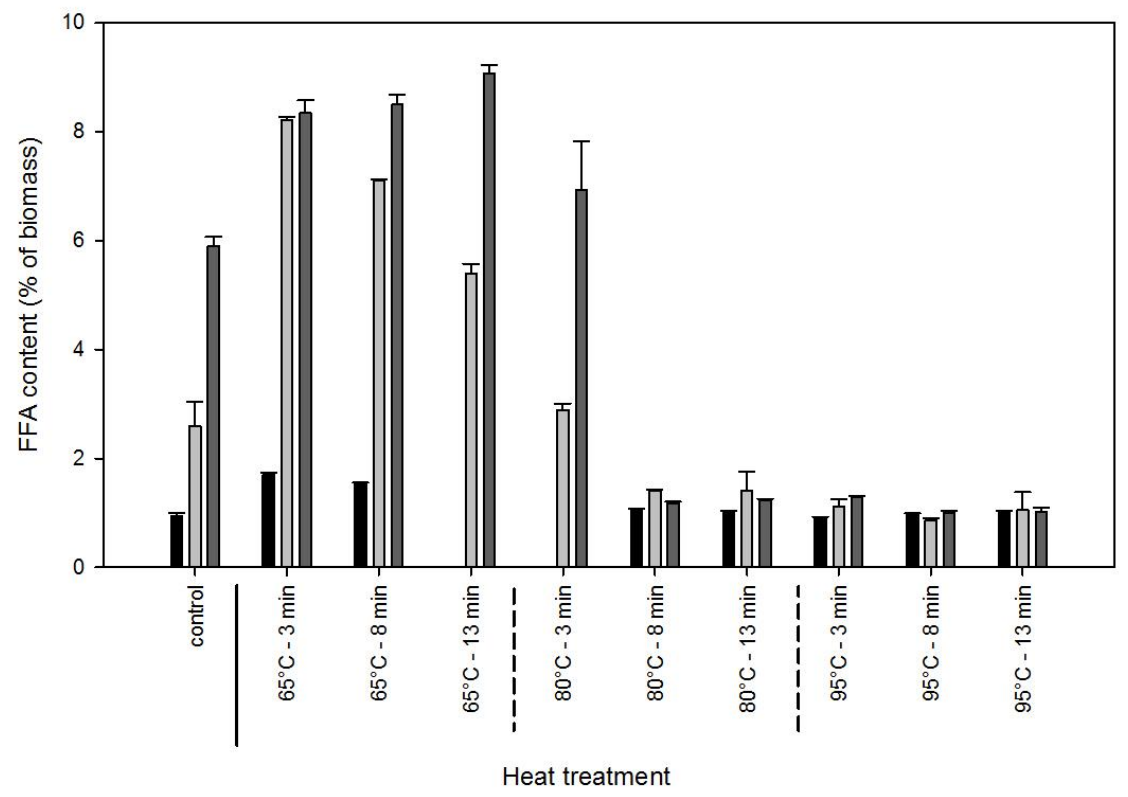

(B)

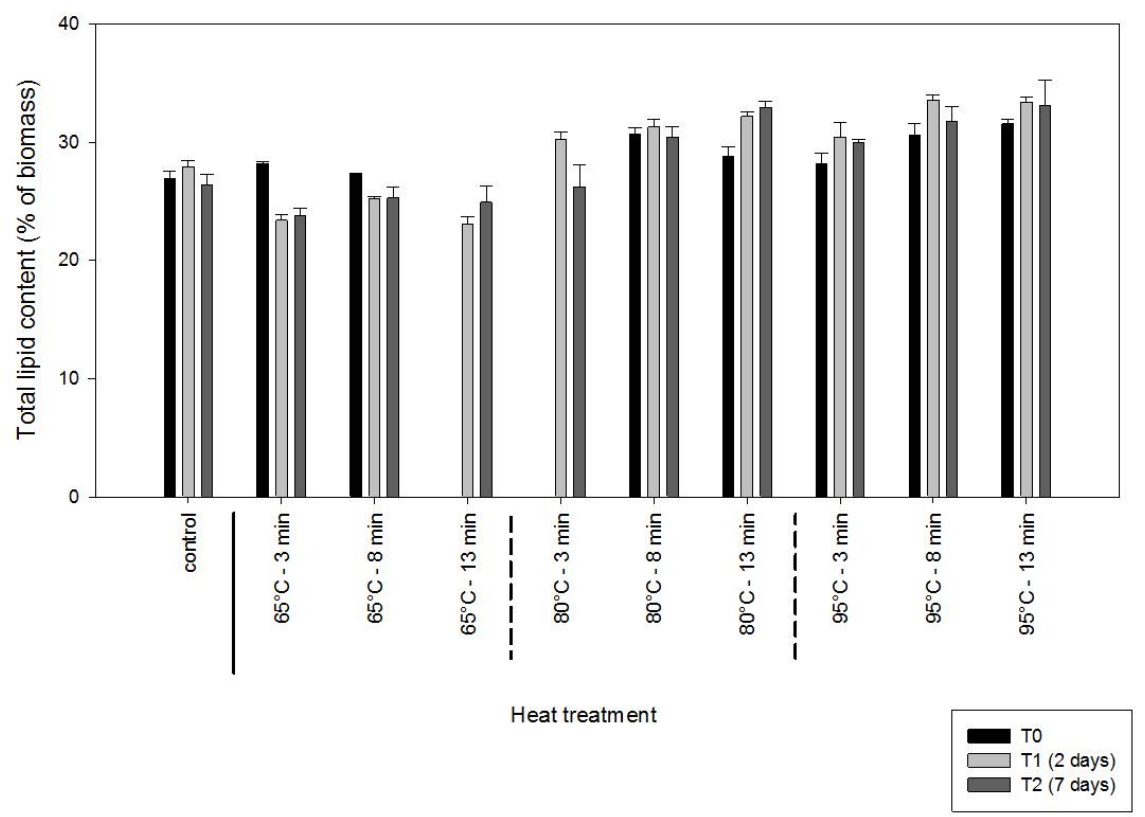

Figure 2: FFA content ( $A$ ) and total lipid content (B) (expressed as percentage of the biomass) of T-Isochrysis lutea samples that were not heat-treated (control) or heat-treated (temperature and time of the treatment indicated) after harvesting and freeze-dried immediately after the heat treatment (TO) or stored at $4^{\circ} \mathrm{C}$ for 2 days (T1) or 7 days (T2) before freeze-drying. Error bars indicate the standard deviations obtained from triplicate measurements. 
In the control biomass, an increase of the FFA content from $0.94 \pm 0.07 \%$ of the biomass (at T0) to $5.90 \pm 0.17 \%$ of the biomass (at T2) was observed. These values are in agreement with the values observed in Balduyck et al. ${ }^{13}$ in the same species under the same storage conditions.

At T0, the FFA content was already higher in biomass treated at $65^{\circ} \mathrm{C}$ compared to the control biomass, which remained at room temperature during the treatments. The elevated temperatures (above room temperature) reached during heating to $65^{\circ} \mathrm{C}$ may have favored the activity of the lipolytic enzymes as these temperatures were closer to the optimal temperature of the enzyme.

However, most importantly, it was shown that wet storage at $4^{\circ} \mathrm{C}$ of the samples treated at $65^{\circ} \mathrm{C}$ resulted in a rapid increase of the FFA content over time (clearly visible despite the lack of data of T0 for one heat treatment) indicating that a temperature of $65^{\circ} \mathrm{C}$ (at least up to $13 \mathrm{~min}$ ) is not sufficient to inactivate the enzymes completely. At longer storage times, the FFA content levelled off to a maximum value of about $8.5 \%$ of the biomass ( $34 \%$ of the total lipids) in all samples treated at $65^{\circ} \mathrm{C}$. This levelling-off effect was also observed by Balduyck et al. ${ }^{13}$ and was attributed to the reaction of FFA with alcohols to form fatty acyl esters.

When applying heat treatments at higher temperatures $\left(80^{\circ} \mathrm{C}\right.$ and $\left.95^{\circ} \mathrm{C}\right)$, the FFA content at T0 was not higher than the control biomass. Apparently, the biomass rapidly reached a temperature that inactivates the lipolytic enzymes, which was not the case at $65^{\circ} \mathrm{C}$.

However, during wet storage, the biomass treated $3 \mathrm{~min}$ at $80^{\circ} \mathrm{C}$ still experienced an increase of the FFA content, clearly visible between T1 and T2 (despite the lack of the data at T0), comparable with the increase of FFA in the control biomass. The other treatments showed no differences between the FFA contents at T0, T1 and T2 and were thus sufficient to completely inactivate the lipolytic enzymes. A sufficient heat treatment (minimum $8 \mathrm{~min}$ at $80^{\circ} \mathrm{C}$ ) thus, enabled lipolytic reactions to stop and to store the treated biomass as a wet paste for 7 days at $4^{\circ} \mathrm{C}$ without FFA formation.

The effect of time and temperature of the heat treatment on the FFA content at T0, T1 and T2 was studied in more detail using a response surface model in treatment time and temperature. Non- 
significant terms were omitted from the three models. The parameter estimates for the significant model terms are presented in Table 1 . The coefficient of determination $\left(R^{2}\right)$ of these models was $0.9981,0.9999$ and 0.9999 for the T0, T1 and T2 data, respectively. To facilitate the interpretation of the significant model terms and the size of the different effects, the final models are visualized by means of contour plots in Figure 3.

Table 1: Estimated effects for the significant terms (non-significant terms have been indicated in italics) in the response surface models for the FFA content in the T-Isochrysis lutea biomass at TO, T1 and T2. Non-significant parameters were removed from the model.

\begin{tabular}{lrrrr} 
Term & Estimate & Std Error & t ratio & Prob $>|\mathbf{t}|$ \\
\hline \hline T0 & & & & \\
\hline Intercept & 1.072 & 0.004 & 259.4 & $<0.0001$ \\
Temp & -0.287 & 0.008 & -35.2 & $<0.0001$ \\
Time & -0.053 & 0.010 & -5.1 & 0.0071 \\
Temp*Temp & 0.184 & 0.009 & 20.2 & $<0.0001$ \\
Temp*Time & 0.104 & 0.013 & 8.2 & 0.0012 \\
& & & & Not \\
Time*Time & & & & significant
\end{tabular}

T1

\begin{tabular}{lrrrr}
\hline Intercept & 1.364 & 0.057 & 23.8 & $<0.0001$ \\
Temp & -3.147 & 0.072 & -43.4 & $<0.0001$ \\
Time & -1.082 & 0.159 & -6.8 & 0.0003 \\
Temp*Temp & 2.601 & 0.093 & 28.0 & $<0.0001$ \\
Temp*Temp & & & & Not \\
Time*Time & & & & significant
\end{tabular}

$\mathrm{T} 2$

\begin{tabular}{lrrrr}
\hline Intercept & 1.193 & 0.114 & 10.5 & $<0.0001$ \\
Temp & -3.766 & 0.093 & -40.6 & $<0.0001$ \\
Temp*Temp & 3.679 & 0.147 & 25.1 & $<0.0001$ \\
Time & & & & \\
Time*Time & & & & Not \\
Time*Temperature & & & & significant
\end{tabular}


(A)

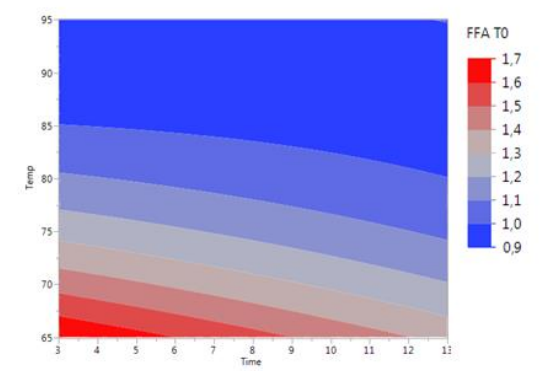

(C)

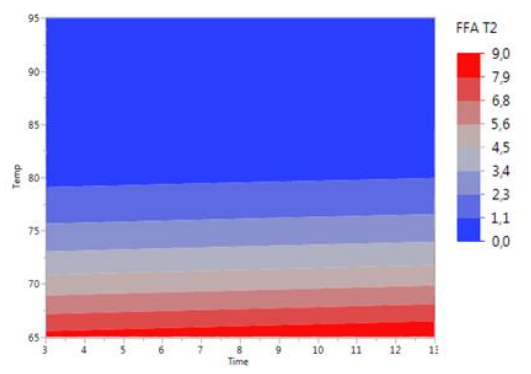

(B)

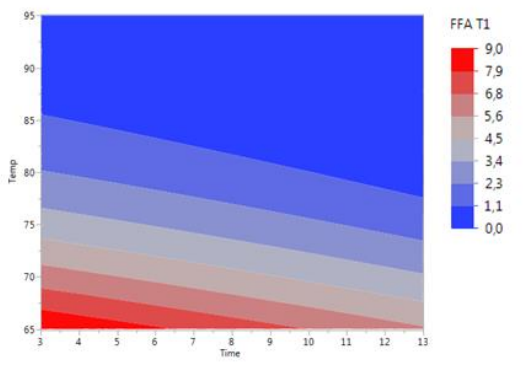

Figure 3: Contour plots showing the FFA content (expressed as percentage of the biomass) in T-Isochrysis lutea samples at TO (A), T1 (B) and T2 (C) as a function of time and temperature of the heat treatment.

At T0, the main effects of temperature and time, the quadratic effect of temperature and the interaction effect of time and temperature were significant on the FFA content. The lower the time and temperature of the treatment, the more active the lipolytic enzymes after the heat treatment, leading to elevated FFA contents immediately after the heat treatment. The quadratic effect of temperature was significant because the negative effect of temperature on the FFA content diminishes at higher temperatures. The contour plot for T0 shows that increasing the temperature beyond $80^{\circ} \mathrm{C}$ did not decrease he FFA content anymore, as the lipolytic enzymes were inactivated above this temperature anyway. The duration of the heat treatment only played a major role when the temperature was below $75^{\circ} \mathrm{C}$.

At $\mathrm{T} 1$ and $\mathrm{T} 2$, the duration of the heat treatment even had a smaller influence, especially at $\mathrm{T} 2$, where none of the model terms involving the variable time were significant. This means that the temperature of the heat treatment was the dominating factor, i.e., the factor with the largest impact on the 
inactivation of the enzymes, given a minimum treatment time of 3 minutes. The quadratic effect of temperature at $\mathrm{T} 1$ and $\mathrm{T} 2$ was similar to that at $\mathrm{T} 0$.

The fact that, at $\mathrm{T} 2$, the effect of treatment time was insignificant, was at odds with the clear difference in FFA formation observed between a treatment of $80^{\circ} \mathrm{C}-3$ minutes and $80^{\circ} \mathrm{C}-8$ minutes shown in Figure 2A. Possibly, this can be explained by the fact that the temperature in the sample after 3 minutes was slightly lower than after 8 minutes, as the treatment temperature $\left(80^{\circ} \mathrm{C}\right)$ is the temperature of the water bath and not the temperature inside the sample (which is given in Figure 1 for two different treatments). The temperature in the sample for the treatment time of 3 minutes was possibly just smaller than the inactivation temperature of the enzymes, which may explain the difference in FFA content between 3 minutes and 8 minutes at $80^{\circ} \mathrm{C}$. This measurement at $80^{\circ} \mathrm{C}-3$ minutes was also identified as an outlier in the statistical analysis of the $\mathrm{T} 2$ data. However, as removing that data point did not noticeably affect the look of the response surface model for T2, we decided to report the results for the full data set for $\mathrm{T} 2$.

These findings are in accordance with the optimum and inactivation temperature of (micro)algal lipases found in literature. In Spirulina platensis, Demir and Tükel ${ }^{18}$ found a maximal enzymatic activity at $45^{\circ} \mathrm{C}$, with an activity range between 37 and $60^{\circ} \mathrm{C}$ and no activity at $70^{\circ} \mathrm{C}$. In Monochrysis lutheri, Bilinski et al. ${ }^{43}$ found a higher optimum temperature of $60^{\circ} \mathrm{C}$ with inactivation of the enzymes at $80^{\circ} \mathrm{C}$. Illijas et al. ${ }^{44}$ and Terasaki and Itabashi ${ }^{19}$ found rather low optimal temperatures (between 25 and $37^{\circ} \mathrm{C}$ ) respectively in Gracilaria vermiculophylla and Chatonella marina. Only Savvidou et al. ${ }^{21}$ found stimulation of the lipolytic activity at very high temperatures $\left(100^{\circ} \mathrm{C}\right)$ in Nannochloropsis oceanica. Except for this last study, these findings from literature confirm the observations made in this study, beingan optimum temperature of the lipolytic enzymes in T-Isochrysis lutea between room temperature and $65^{\circ} \mathrm{C}$ and inactivation of these enzymes from $80^{\circ} \mathrm{C}$.

The lipid contents (Figure 2B) at TO did not show clear differences as a function of heat treatment applied. 
On the other hand, Figure 2 shows that, in the biomass samples in which the FFA content increased strongly over time, the lipid content decreased over the same time. For example, the increase of the FFA content from $\mathrm{T} 0$ to $\mathrm{T} 1$ in the samples treated at $65^{\circ} \mathrm{C}$ was accompanied by a decrease of the lipid contentAlso the increase of the FFA content from $\mathrm{T} 1$ to $\mathrm{T} 2$ in the sample treated for $3 \mathrm{~min}$ at $80^{\circ} \mathrm{C}$ was concomitant with a decrease of the lipid content. As lipolysis causes release of FFA from the head groups of lipids (both neutral, phospho- and glycolipids), these head groups may consequently dissolve in the aqueous layer during the extraction procedure, leading to a decrease of the gravimetrically determined lipid content. A similar effect was observed by Ryckebosch et al. ${ }^{45}$ in Phaeodactylum tricornutum. As approximately one third of the lipids in T-Isochrysis lutea are polar lipids (phospholipids and glycolipids) ${ }^{39}$, in which the head group is more extensive, this can account for a significant part of the weight. The correlation between the lipid content and the FFA content at T1 and T2 wascalculated to be 0.932 and 0.942 , showing again that these two parameters are very strongly correlated.

\subsection{Influence of selected heat treatments on quality attributes}

In a second experiment of this study, two heat treatments were selected by which the enzymatic activity of the lipolytic enzymes was stopped: a longer time at a slightly milder temperature ( $8 \mathrm{~min}$ at $\left.80^{\circ} \mathrm{C}, \mathrm{TRT} 1\right)$ and a short time at a very high temperature ( $3 \mathrm{~min}$ at $\left.95^{\circ} \mathrm{C}, \mathrm{TRT} 2\right)$. These two treatments were compared with the control treatment (without heat treatment, CONTR) to investigate the influence of the heat treatments on the quality attributes of the biomass (oxidative stability, carotenoid composition and quantity, phenolic content and omega-3 fatty acid content).

The total lipid content (Figure 4A) and the FFA content (Figure 4B) showed the same observations as in the first part of this study. Extensive lipolysis was observed in the control biomass during wet storage at $4^{\circ} \mathrm{C}$ for 1 week, causing a strongly increasing FFA content (from $0.24 \pm 0.01 \%$ to $6.19 \pm 0.19 \%$ of the biomass) and a decreasing total lipid content (from $26.9 \pm 0.5 \%$ to $24.3 \pm 0.7 \%$ of the biomass). In the heat-treated samples, only a slight increase of the FFA content was observed and no changes in the total lipid content, demonstrating again the usefulness of these heat treatments to prevent 
lipolytic reactions during wet storage at $4^{\circ} \mathrm{C}$. Slight differences between the first and second part of this study are possibly due to small differences during cultivation, as two different batches were used.
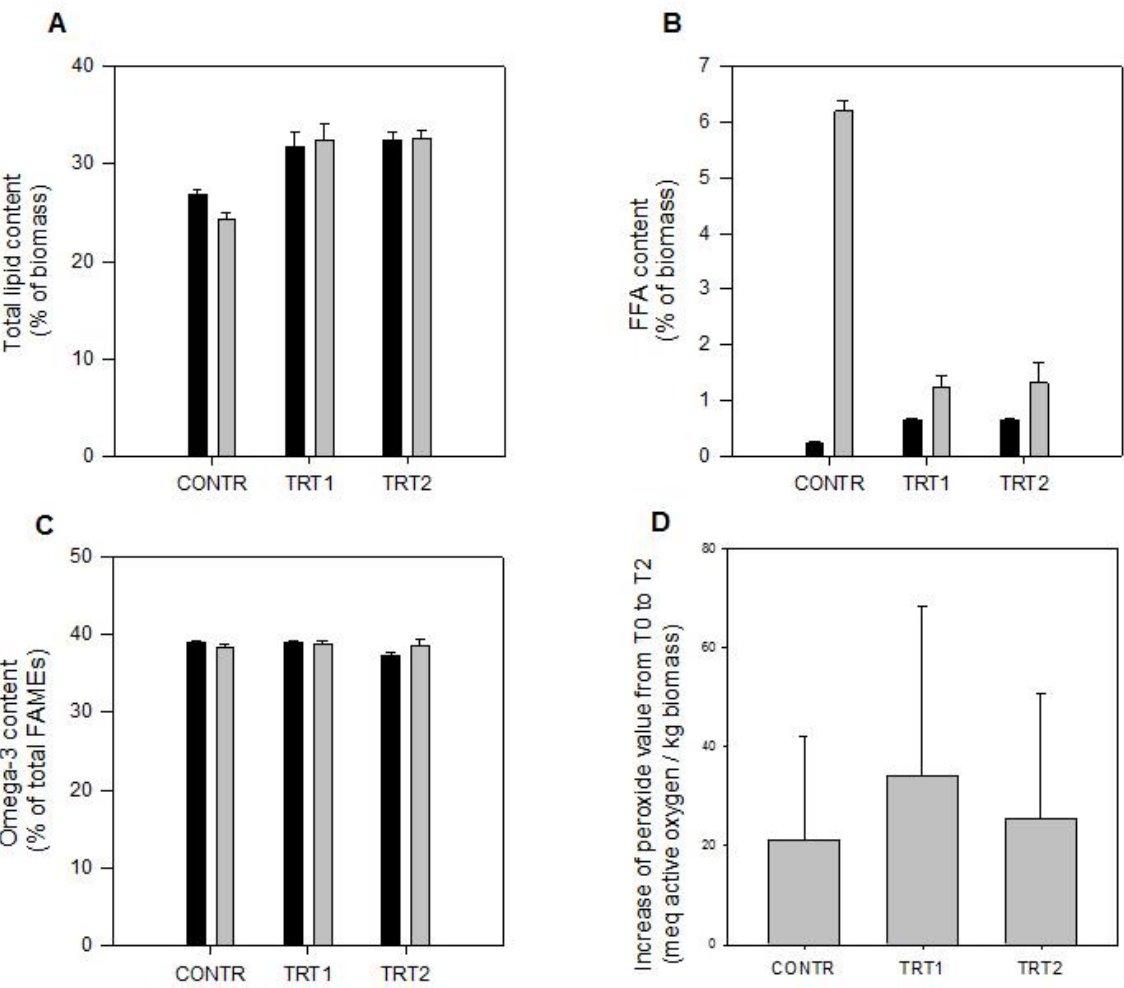

E

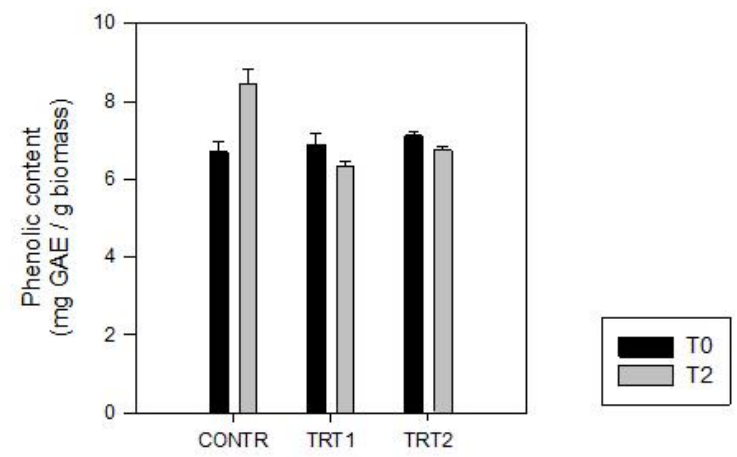

Figure 4: Comparison of the quality attributes in T-Isochrysis lutea samples that were not heat-treated (CONTR), treated at $80^{\circ} \mathrm{C}$ for $8 \mathrm{~min}(T R T 1)$ or treated at $95^{\circ} \mathrm{C}$ for $3 \mathrm{~min}$ (TRT2) after harvesting and consequently freezedried immediately (TO) or stored at $4^{\circ} \mathrm{C}$ for 7 days before freeze-drying (T2). Error bars indicate standard deviations obtained from triplicate measurements. 
The relative fatty acid composition (expressed as percentage of total FAME) and consequently also the relative amount of omega-3 fatty acids (Figure 4C) did not change by the heat treatments nor by the lipolytic reactions observed in the control biomass. The main fatty acids in the lipid fraction were myristic acid (C14:0, $16.8 \pm 0.5 \%$ ), palmitic acid (C16:0, $7.9 \pm 0.1 \%)$, palmitoleic acid (C16:1, $10.9 \pm 1.1 \%)$, oleic acid (C18:1, $8.4 \pm 0.6 \%)$, linoleic acid (C18:2, $9.8 \pm 0.2 \%), \alpha$-linolenic acid (C18:3n-3, $13.4 \pm 0.1 \%)$, stearidonic acid $(\mathrm{C} 18: 4 n-3,13.7 \pm 0.5 \%)$ and docosahexaenoic acid (C22:6n-3, 10.8 $\pm 0.4 \%$ ). When determining the FAME composition, all fatty acids (whether they are present as FFA or bound to a lipid core in TAG or polar lipids) are released and converted to methyl esters. Therefore the lipolysis was not visible in the FAME composition. Furthermore, the heat treatments did not lead to a loss of omega-3 fatty acids by polymerization, as was observed in Gheysen et al. ${ }^{46}$.

The peroxide value, as a measure of primary lipid oxidation, was analyzed during wet storage. The increase of the peroxide value from $\mathrm{T} 0$ to $\mathrm{T} 2$ is shown in Figure 4D for each of the treatments. It was found that the peroxide value increased during wet storage, both in the control biomass and the heattreated biomass. However, there was no difference between the control sample and the heat-treated samples. Although these results need to be confirmed by data for the secondary oxidation products, the oxidative stability for short-term ( 1 week) storage at $4^{\circ} \mathrm{C}$ was not diminished by the heat treatment. More extensive studies are however necessary to reveal whether this is also the case during longer term storage. Oxidation of fatty acids can either be enzymatically catalyzed or initiated by free radicals (autoxidation) or singlet oxygen (photo-oxidation) ${ }^{47}$. The equal extent of oxidation in all samples points out that oxidation is either not enzyme catalyzed or the lipoxygenases are more heat stable than the lipases and not inactivated by the heat treatment applied. If lipoxygenases are inactivated during the heat treatment, a higher activity would be expected in the non-treated biomass, which would give a higher peroxide value. Oxidation is normally promoted as temperature rises and by the presence of light and can be delayed by the presence of antioxidants ${ }^{11,48}$. Possibly, the heat treatments used here are not intense or long enough to promote oxidation reactions and/or to degrade the present antioxidants. 
T-Isochrysis biomass has been demonstrated to possess a good antioxidative activity, which has been attributed to the presence of phenolic compounds and several carotenoids ${ }^{40}$. These antioxidants are known to delay the onset of lipid oxidation by scavenging lipid-derived radicals, quenching singlet oxygen (in the case of beta-carotene) and/or chelating metals ${ }^{40,49,50}$. In addition, this antioxidant activity can be useful in protecting humans against several disorders (e.g., atherosclerosis, inflammatory diseases and diabetes) ${ }^{50,51}$. It is thus of major importance to know whether these compounds remain stable during the proposed heat treatments. Therefore, the influence of the heat treatments on the amount of both antioxidant groups was investigated. The results are presented in Figure 4E (phenolic compounds) and Figure 5 (carotenoids and chlorophylls).

The phenolic content (Figure 4E) in T-Isochrysis lutea was around 6.5 to $7 \mathrm{mg}$ Gallic Acid Equivalents (GAE) per g biomass, which is in between the values found by Goiris et al. ${ }^{40}$ ( $2.67 \pm 0.22 \mathrm{mg} \mathrm{GAE} / \mathrm{g}$ biomass in T-Isochrysis and $4.57 \pm 0.18 \mathrm{mg} \mathrm{GAE} / \mathrm{g}$ biomass in Isochrysis sp.) and by Maadane et al. ${ }^{52}$ (13.4 $\pm 0.16 \mathrm{mg} \mathrm{GAE} / \mathrm{g}$ biomass). The phenolic content was only different in the control sample at T2. This sudden difference compared to the other samples could not be explained and is possibly due to a random error. It can, thus, be concluded that phenolic compounds present in T-Isochrysis lutea biomass are not sensitive to the proposed heat treatments as they are present in both the control and the heat-treated biomass in equal amounts. 

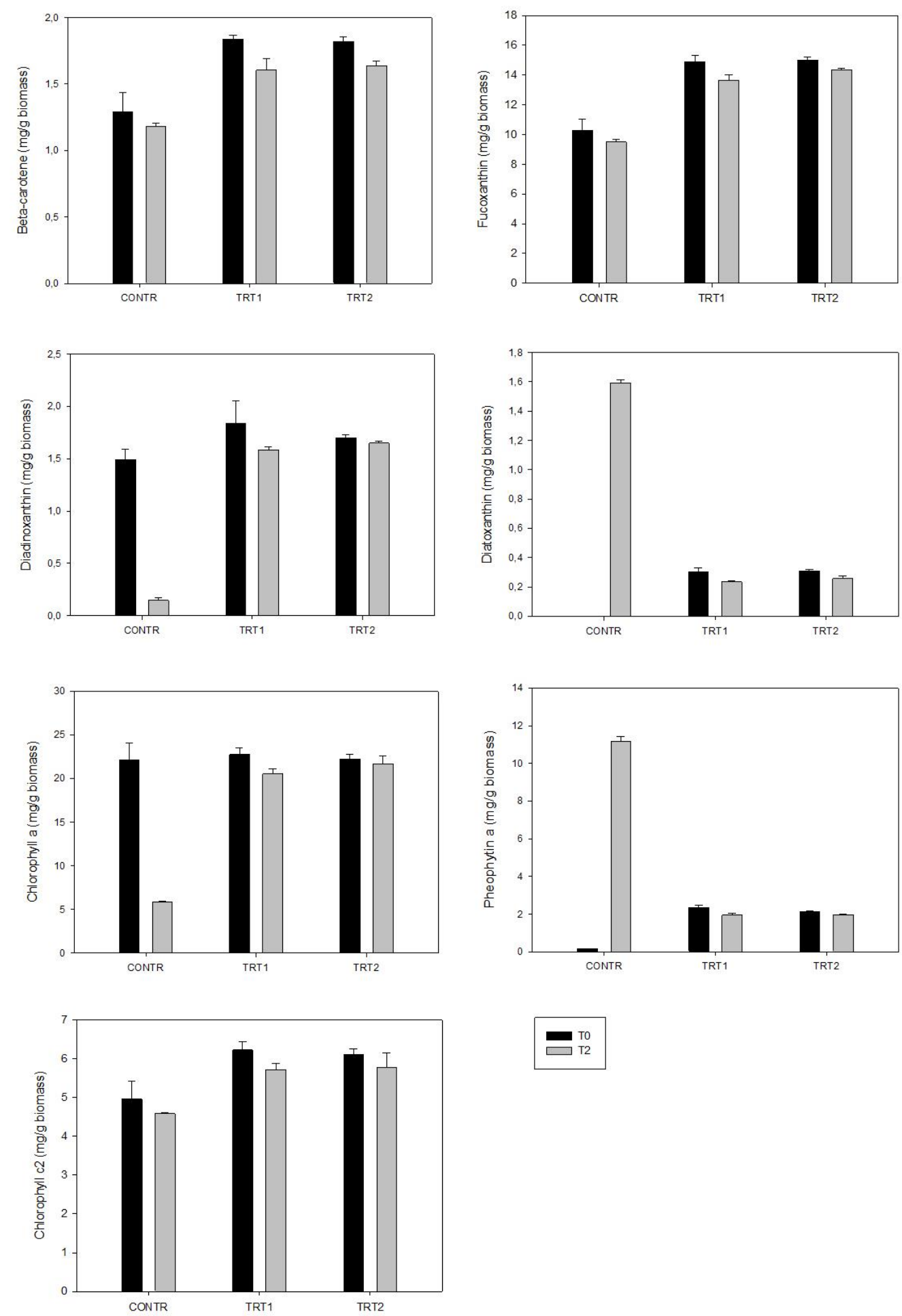

$$
\boldsymbol{\sigma}_{\text {T2 }}^{\text {T0 }}
$$

Figure 5: Comparison of the carotenoid content in T-Isochrysis lutea samples that were not heat-treated (CONTR), treated at $80^{\circ} \mathrm{C}$ for $8 \mathrm{~min}(T R T 1)$ or treated at $95^{\circ} \mathrm{C}$ for $3 \mathrm{~min}$ (TRT2) after harvesting and consequently freezedried immediately (TO) or stored at $4^{\circ} \mathrm{C}$ for 7 days before freeze-drying (T2). Error bars indicate standard deviations obtained from triplicate measurements. 
Seven different pigments were identified in the T-Isochrysis lutea samples: beta-carotene, fucoxanthin, diadinoxanthin, diatoxanthin, chlorophyll a, pheophytin a and chlorophyll c2 (Figure 5). This approximately corresponds with the pigments observed in other studies on Isochrysis galbana ${ }^{53}$ and T-Isochrysis lutea ${ }^{54}$. It was observed that the amounts of beta-carotene, fucoxanthin and chlorophyll c2 did not decrease during wet storage at $4^{\circ} \mathrm{C}$. However, the amount of these compounds was lower in the control biomass than in the heat-treated biomass. Two possible explanations for this observation can be proposed. First, although the extraction procedure was optimized thoroughly before this experiment, it is possible that the extraction efficiency is improved by the heat treatment. Damage to the cells can be a consequence of this treatment, which could improve extraction of pigments. However, this is not likely, because T-Isochrysis lutea has no or only a very thin cell wall, which is not likely to limit the extraction of pigments from inside the cells. Secondly, it is possible that the heat treatment causes the release of carotenoids and chlorophylls from complexes with proteins ${ }^{55}$, enabling their extraction only in the heat-treated samples.

It was observed that the diadinoxanthin content decreased during wet storage of the control biomass, while at the same time the diatoxanthin content increased. This was not the case in the heat-treated biomass, in which the diadinoxanthin and diatoxanthin content remained almost constant during wet storage. This can be explained by the enzymatic conversion of diadinoxanthin to diatoxanthin in the control biomass ${ }^{55}$, while the responsible enzyme was probably inactivated by the heat treatment. Possibly, some enzymatic activity during the warming-up phase of the heat treatment (before inactivation of the enzyme) caused the slightly higher amount of diatoxanthin in the heat-treated samples than in the control sample at T0. The same observation could be made for the conversion of chlorophyll a to pheophytin a. Breakdown of chlorophyll a to pheophytin a was observed during storage in the control biomass, while no changes in both compounds were seen in the heat-treated samples. This implies that the conversion of chlorophyll a to pheophytin a in the control biomass is 
catalyzed by enzymes that are inactivated by the heat treatments. The conversion from chlorophyll a to pheophytin a, which includes the removal of the magnesium atom from the chlorophyll a molecule, is also accompanied by a color change from blue-green to olive green. Consequently, the heat treatment also improves color retention in the microalgal biomass. The chlorophyll a content at T0 was not differing between the treatments, which means that the heat treatment is not strong enough to induce heat related degradation of chlorophyll a.

It can be concluded that some pigments (chlorophyll a, diadinoxanthin) remained stable during wet storage after the heat treatment, while this was not the case in biomass that was not heat-treated. For none of the observed pigments there was a decrease as a result of the heat treatment. Overall, the heat treatment, thus, has no negative influence on the pigment content of the biomass. On the contrary, it stabilizes the amount of some pigments and helps to preserve the color.

\section{Conclusion}

The results of this study imply that a heat treatment of the wet biomass paste before storage can be a solution for the lipolytic stability problems. In microalgae ruptured during harvesting or thathave to be disrupted to enable extraction of interesting compounds, lipolysis normally starts very rapidly ${ }^{14}$. By applying a heat treatment before or immediately after the step in which rupture occurs, the formation of substantial and problematic amounts of FFA can be avoided. Also before wet extractions, a heat treatment could be useful to inhibit lipolytic reactions during the extraction procedure. A timetemperature combination of at least 8 minutes at $80^{\circ} \mathrm{C}$ was found to be sufficient for T-Isochrysis lutea, but this could be species dependent. 


\section{Acknowledgements}

This work was supported by Flanders Innovation \& Entrepreneurship (VLAIO strategic research grant

L. Balduyck).

Required statements and declarations

- Declaration of authors contributions:

We declare that all authors have contributed to the conception and design of the study, or acquisition of data, or analysis and interpretation of the data, or drafting and revising the article, and approved the final version to be submitted.

- Conflict of interest statement:

There are no declarations of interest.

- Statement of Informed Consent, Human/Animal Rights

No conflicts, informed consent, human or animal rights applicable

- Declaration of authors agreement

We declare that all authors agree with the submission. 
1. Plaza, M.; Herrero, M.; Cifuentes, A.; Ibanez, E., Innovative Natural Functional Ingredients from Microalgae. Journal of Agricultural and Food Chemistry 2009, 57 (16), 7159-7170.

2. Bahadar, A.; Khan, M. B., Progress in energy from microalgae: A review. Renewable \& Sustainable Energy Reviews 2013, 27, 128-148.

3. Calder, P. C., Very long chain omega-3 (n-3) fatty acids and human health. European Journal of Lipid Science and Technology 2014, 116 (10), 1280-1300.

4. Spolaore, P.; Joannis-Cassan, C.; Duran, E.; Isambert, A., Commercial applications of microalgae. Journal of Bioscience and Bioengineering 2006, 101 (2), 87-96.

5. Li, L.; Cui, J.; Liu, Q.; Ding, Y. C.; Liu, J. G., Screening and phylogenetic analysis of lipid-rich microalgae. Algal Research-Biomass Biofuels and Bioproducts 2015, 11, 381-386.

6. Veillette, M.; Giroir-Fendler, A.; Faucheux, N.; Heitz, M., Esterification of free fatty acids with methanol to biodiesel using heterogeneous catalysts: From model acid oil to microalgae lipids. Chemical Engineering Journal 2017, 308, 101-109.

7. López, E. N.; Medina, A. R.; Moreno, P. A. G.; Callejón, M. J. J.; Cerdán, L. E.; Valverde, L. M.; López, B. C.; Grima, E. M., Enzymatic production of biodiesel from Nannochloropsis gaditana lipids: influence of operational variables and polar lipid content. Bioresource technology 2015, 187, 346-353.

8. Juttner, F., Liberation of 5,8,11,14,17-eicosapentaenoic acid and other polyunsaturated fatty acids from lipids as a grazer defense reaction in epilithic diatom biofilms. Journal of Phycology 2001, 37 (5), 744-755.

9. Doblado-Maldonado, A. F.; Pike, O. A.; Sweley, J. C.; Rose, D. J., Key issues and challenges in whole wheat flour milling and storage. Journal of Cereal Science 2012, 56 (2), 119-126.

10. Aubourg, S. P., Fluorescence study of the pro-oxidant effect of free fatty acids on marine lipids. Journal of the Science of Food and Agriculture 2001, 81 (4), 385-390.

11. Gordon, M. H., The development of oxidative rancidity in food. In Antioxidants in food. Practical applications, Pokorny, J.; Yanishlieva, N.; Gordon, M. H., Eds. CRC Press: Boca Raton, 2001; pp 7-20.

12. Singer, P.; Ruhe, J., On the mechanism of deposit formation during thermal oxidation of mineral diesel and diesel/biodiesel blends under accelerated conditions. Fuel 2014, 133, 245-252.

13. Balduyck, L.; Bijttebier, S.; Bruneel, C.; Jacobs, G.; Voorspoels, S.; Van Durme, J.; Muylaert, K.; Foubert, I., Lipolysis in T-Isochrysis lutea during wet storage at different temperatures. Algal ResearchBiomass Biofuels and Bioproducts 2016, 18, 281-287.

14. Balduyck, L.; Stock, T.; Bijttebier, S.; Bruneel, C.; Jacobs, G.; Voorspoels, S.; Muylaert, K.; Foubert, l., Integrity of the microalgal cell plays a major role in the lipolytic stability during wet storage. Algal Research-Biomass Biofuels and Bioproducts 2017, 25, 516-524.

15. Chen, L.; Liu, T. Z.; Zhang, W.; Chen, X. L.; Wang, J. F., Biodiesel production from algae oil high in free fatty acids by two-step catalytic conversion. Bioresource Technology 2012, 111, 208-214.

16. Angles, E.; Jaouen, P.; Pruvost, J.; Marchal, L., Wet lipid extraction from the microalga Nannochloropsis sp.: Disruption, physiological effects and solvent screening. Algal Research-Biomass Biofuels and Bioproducts 2017, 21, 27-34.

17. Beacham, T. A.; Bradley, C.; White, D. A.; Bond, P.; Ali, S. T., Lipid productivity and cell wall ultrastructure of six strains of Nannochloropsis: Implications for biofuel production and downstream processing. Algal Research-Biomass Biofuels and Bioproducts 2014, 6, 64-69.

18. Demir, B. S.; Tukel, S. S., Purification and characterization of lipase from Spirulina platensis. Journal of Molecular Catalysis B-Enzymatic 2010, 64 (3-4), 123-128.

19. Terasaki, M.; Itabashi, Y., Free Fatty Acid Level and Galactolipase Activity in a Red Tide Flagellate Chattonella marina (Raphidophyceae). Journal of Oleo Science 2002, 51 (3), 213-218. 
20. Yong, S. K.; Lim, B. H.; Saleh, S.; Tey, L. H., Optimisation, purification and characterisation of extracellular lipase from Botryococcus sudeticus (UTEX 2629). Journal of Molecular Catalysis BEnzymatic 2016, 126, 99-105.

21. Savvidou, M. G.; Sotiroudis, T. G.; Kolisis, F. N., Cell surface and cellular debris-associated heatstable lipolytic enzyme activities of the marine alga Nannochloropsis oceanica. Biocatalysis and Biotransformation 2016, 34 (1), 24-32.

22. Godet, S.; Herault, J.; Pencreac'h, G.; Ergan, F.; Loiseau, C., Isolation and analysis of a gene from the marine microalga Isochrysis galbana that encodes a lipase-like protein. Journal of Applied Phycology 2012, 24 (6), 1547-1553.

23. Kerviel, V.; Herault, J.; Dumur, J.; Ergan, F.; Poisson, L.; Loiseau, C., Cloning and expression of a gene from Isochrysis galbana modifying fatty acid profiles in Escherichia coli. Journal of Applied Phycology 2014, 26 (5), 2109-2115.

24. Hubert, F.; Poisson, L.; Loiseau, C.; Gauvry, L.; Pencreac'h, G.; Herault, J.; Ergan, F., Lipids and lipolytic enzymes of the microalga Isochrysis galbana. Ocl-Oilseeds and Fats Crops and Lipids 2017, 24 (4), 7.

25. Barka, F.; Angstenberger, M.; Ahrendt, T.; Lorenzen, W.; Bode, H. B.; Buchel, C., Identification of a triacylglycerol lipase in the diatom Phaeodactylum tricornutum. Biochimica Et Biophysica ActaMolecular and Cell Biology of Lipids 2016, 1861 (3), 239-248.

26. Berge, J. P.; Gouygou, J. P.; Dubacq, J. P.; Durand, P., Reassessment of lipid-composition of the diatom Skeletonema Costatum Phytochemistry 1995, 39 (5), 1017-1021.

27. Budge, S. M.; Parrish, C. C., Lipid class and fatty acid composition of Pseudo-nitzschia multiseries and Pseudo-nitzschia pungens and effects of lipolytic enzyme deactivation. Phytochemistry 1999, 52 (4), 561-566.

28. Ramezanzadeh, F. M.; Rao, R. M.; Windhauser, M.; Prinyawiwatkul, W.; Tulley, R.; Marshall, W. E., Prevention of hydrolytic rancidity in rice bran during storage. Journal of Agricultural and Food Chemistry 1999, 47 (8), 3050-3052.

29. Lehtinen, P.; Kiiliainen, K.; Lehtomaki, K.; Laakso, S., Effect of heat treatment on lipid stability in processed oats. Journal of Cereal Science 2003, 37 (2), 215-221.

30. Gerits, L. R.; Pareyt, B.; Decamps, K.; Delcour, J. A., Lipases and Their Functionality in the Production of Wheat-Based Food Systems. Comprehensive Reviews in Food Science and Food Safety 2014, 13 (5), 978-989.

31. Wu, J.; McClements, D. J.; Chen, J.; Hu, X.; Liu, C., Improvement in nutritional attributes of rice using superheated steam processing. Journal of Functional Foods 2016, 24, 338-350.

32. De Almeida, J. L.; Pareyt, B.; Gerits, L. R.; Delcour, J. A., Effect of Wheat Grain Steaming and Washing on Lipase Activity in Whole Grain Flour. Cereal Chemistry 2014, 91 (4), 321-326.

33. Barros, M.; Fleuri, L. F.; Macedo, G. A., Seed lipases: sources, applications and properties - a review. Brazilian Journal of Chemical Engineering 2010, 27 (1), 15-29.

34. Shahidi, F.; Ambigaipalan, P., Phenolics and polyphenolics in foods, beverages and spices: Antioxidant activity and health effects - A review. Journal of Functional Foods 2015, 18, 820-897.

35. Guillard, R. R.; Lorenzen, C. J., Yellow-green algae with chlorophyllide c. Journal of Phycology 1972, $8(1), 10-\&$.

36. Ryckebosch, E.; Muylaert, K.; Foubert, I., Optimization of an Analytical Procedure for Extraction of Lipids from Microalgae. Journal of the American Oil Chemists Society 2012, 89 (2), 189-198.

37. Kangani, C. O.; Kelley, D. E.; DeLany, J. P., New method for GC/FID and GC-C-IRMS analysis of plasma free fatty acid concentration and isotopic enrichment. Journal of Chromatography B-Analytical Technologies in the Biomedical and Life Sciences 2008, 873 (1), 95-101.

38. Lemahieu, C.; Bruneel, C.; Termote-Verhalle, R.; Muylaert, K.; Buyse, J.; Foubert, I., Impact of feed supplementation with different omega- 3 rich microalgae species on enrichment of eggs of laying hens. Food Chemistry 2013, 141 (4), 4051-4059.

39. Ryckebosch, E.; Bruneel, C.; Termote-Verhalle, R.; Lemahieu, C.; Muylaert, K.; Van Durme, J.; Goiris, K.; Foubert, I., Stability of Omega-3 LC-PUFA-rich Photoautotrophic Microalgal Oils Compared 
to Commercially Available Omega-3 LC-PUFA Oils. Journal of Agricultural and Food Chemistry 2013, 61 (42), 10145-10155.

40. Goiris, K.; Muylaert, K.; Fraeye, I.; Foubert, I.; De Brabanter, J.; De Cooman, L., Antioxidant potential of microalgae in relation to their phenolic and carotenoid content. Journal of Applied Phycology 2012, 24 (6), 1477-1486.

41. Goos, P.; Jones, B., Optimal design of experiments: a case study approach. John Wiley \& Sons: 2011.

42. Myers, R. H.; Montgomery, D. C.; Anderson-Cook, C. M., Response surface methodology: process and product optimization using designed experiments. John Wiley \& Sons: 2016.

43. Bilinski, E.; Antia, N. J.; Lau, Y. C., Characterization of phospholipase c from a marine planktonic alga (Monochrysis lutheri) Biochimica Et Biophysica Acta 1968, 159 (3), 496-\&.

44. Illijas, M. I.; Terasaki, M.; Nakamura, R.; lijima, N.; Hara, A.; Fusetani, N.; Itabashi, Y., Purification and characterization of glycerolipid acyl-hydrolase from the red alga Gracilaria vermiculophylla. Fisheries Science 2008, 74 (3), 670-676.

45. Ryckebosch, E.; Muylaert, K.; Eeckhout, M.; Ruyssen, T.; Foubert, I., Influence of Drying and Storage on Lipid and Carotenoid Stability of the Microalga Phaeodactylum tricornutum. Journal of Agricultural and Food Chemistry 2011, 59 (20), 11063-11069.

46. Gheysen, L.; Bernaerts, T.; Bruneel, C.; Goiris, K.; Van Durme, J.; Van Loey, A.; De Cooman, L.; Foubert, I., Impact of processing on n-3 LC-PUFA in model systems enriched with microalgae. Food Chemistry 2018, 268, 441-450.

47. Knothe, G.; Kenar, J. A.; Gunstone, F. D., Chemical properties. In The lipid handbook, 3 ed.; Gunstone, F. D.; Harwood, J. L.; Dijkstra, A. J., Eds. CRC Press: Boca Raton, 2007; pp 535-587.

48. Knothe, G., Some aspects of biodiesel oxidative stability. Fuel Processing Technology 2007, 88 (7), 669-677.

49. Safafar, H.; van Wagenen, J.; Moller, P.; Jacobsen, C., Carotenoids, Phenolic Compounds and Tocopherols Contribute to the Antioxidative Properties of Some Microalgae Species Grown on Industrial Wastewater. Marine Drugs 2015, 13 (12), 7339-7356.

50. Christaki, E.; Bonos, E.; Giannenas, I.; Florou-Paneri, P., Functional properties of carotenoids originating from algae. Journal of the Science of Food and Agriculture 2013, 93 (1), 5-11.

51. Maiani, G.; Caston, M. J. P.; Catasta, G.; Toti, E.; Cambrodon, I. G.; Bysted, A.; GranadoLorencio, F.; Olmedilla-Alonso, B.; Knuthsen, P.; Valoti, M.; Bohm, V.; Mayer-Miebach, E.; Behsnilian, D.; Schlemmer, U., Carotenoids: Actual knowledge on food sources, intakes, stability and bioavailability and their protective role in humans. Molecular Nutrition \& Food Research 2009, 53, S194-S218.

52. Maadane, A.; Merghoub, N.; Ainane, T.; El Arroussi, H.; Benhima, R.; Amzazi, S.; Bakri, Y.; Wahby, I., Antioxidant activity of some Moroccan marine microalgae: Pufa profiles, carotenoids and phenolic content. Journal of Biotechnology 2015, 215, 13-19.

53. Gilbert-Lopez, B.; Mendiola, J. A.; Fontecha, J.; van den Broek, L. A. M.; Sijtsma, L.; Cifuentes, A.; Herrero, M.; Ibanez, E., Downstream processing of Isochrysis galbana: a step towards microalgal biorefinery. Green Chemistry 2015, 17 (9), 4599-4609.

54. Mulders, K. J. M.; Weesepoel, Y.; Lamers, P. P.; Vincken, J. P.; Martens, D. E.; Wijffels, R. H., Growth and pigment accumulation in nutrient-depleted Isochrysis aff. galbana T-ISO. Journal of Applied Phycology 2013, 25 (5), 1421-1430.

55. Bertrand, M., Carotenoid biosynthesis in diatoms. Photosynthesis Research 2010, 106 (1-2), 89-102. 